\title{
Subjective norms, attitudes, body mass indices, and self esteem as influences on women's body image behavior
}

Amy Martha Rogers

West Virginia University

Follow this and additional works at: https://researchrepository.wvu.edu/etd

\section{Recommended Citation}

Rogers, Amy Martha, "Subjective norms, attitudes, body mass indices, and self esteem as influences on women's body image behavior" (2000). Graduate Theses, Dissertations, and Problem Reports. 1137. https://researchrepository.wvu.edu/etd/1137

This Thesis is protected by copyright and/or related rights. It has been brought to you by the The Research Repository @ WVU with permission from the rights-holder(s). You are free to use this Thesis in any way that is permitted by the copyright and related rights legislation that applies to your use. For other uses you must obtain permission from the rights-holder(s) directly, unless additional rights are indicated by a Creative Commons license in the record and/ or on the work itself. This Thesis has been accepted for inclusion in WVU Graduate Theses, Dissertations, and Problem Reports collection by an authorized administrator of The Research Repository @ WVU. For more information, please contact researchrepository@mail.wvu.edu. 
Subjective Norms, Attitudes, Body Mass Indices, and Self Esteem as Influences on Women's Body Image Behavior

\section{Amy M. Rogers}

Thesis submitted to the School of Medicine at West Virginia University in partial fulfillment of the requirements for the degree of

Master of Science in Community Health Education

Irene Tessaro, Dr.PH., Chair

Ruth Kershner, RN, CHES, Ed.D.

William Reger, Ed.D.

Department of Community Medicine

Morgantown, West Virginia

2000

Keywords: Women, Body Image, Theory of Reasoned Action

Copyright Amy M. Rogers, 2000 


\begin{abstract}
Subjective Norms, Attitudes, Body Mass Indices, and Self Esteem as Influences on Women's Body Image Behavior
\end{abstract}

Amy M. Rogers

The purpose of this study was to demonstrate associations between perception of body image among women and their body image behaviors. A study was needed to determine the extent to which subjective norms, attitudes, beliefs, Body Mass Index, and self esteem were associated with body image behaviors. The target population in this study was female students at West Virginia University. Data collection was facilitated through an anonymous mailed questionnaire sent to 400 female students at West Virginia University. Components of Theory of Reasoned Action were used to develop a questionnaire. Questions assessed participants' attitudes and beliefs, subjective norms, and outcomes from contemplating their personal body image. Results of the survey indicated self esteem and the influence of magazine models were associated with individual body satisfaction. In addition, self esteem and social networks were associated with body image behaviors (which included purchasing cosmetics and fashions, and dieting). Having high self esteem was correlated with high body satisfaction. Also, women who placed greater importance on television celebrities and fashion models, reported less body satisfaction than women who reported less importance of celebrities and models in shaping their perceptions. Finally, women who agreed with the statement "people who are important to me think my appearance is just right," reported higher levels of body satisfaction. This study indicates there are significant associations between body image components and behaviors which result from the interaction among those components. 
To my mom Tracy, and my sisters Lisa, Zoey, Phoebe, and Marlee 


\section{ACKNOWLEDGMENTS}

I would like to thank the following faculty members for their assistance. Thank you Dr. Irene Tessaro for spending countless hours reading, revising, and directing me to produce better work. Thank you Dr. Ruth Kershner for initially sending me in the right direction, and later making meticulous revisions to my work. Thank you Dr. Bill Reger for being a constant source of support throughout this process. Thank you Dr. Gerry Hobbs for helping with my statistical analysis.

I would also like to acknowledge my family and friends for their support. Thanks for providing the inspiration and motivation needed to begin (and finish!) this project. 


\section{TABLE OF CONTENTS}

CHAPTER 1: Introduction___p.1

Statement of Research Problem___ p.1

Significance of the Proposed Work__ p.2

Study Objectives_p p.2

Research Questions__ p.2

Hypotheses_ p.3

CHAPTER 2: Background___ p.5

Review of the Literature _ p.5

Theoretical Framework__p.11

CHAPTER 3: Research Methods___ _ _ 13

Research Design__ p.13

Study Population_ p.13

Data Collection_p.13

Analysis_p.14

CHAPTER 4: Results__ p.18

Characteristics of Sample__ p.18

Findings/Themes__ p.20

CHAPTER 5: Discussion___ _ _ 26

Major Findings_p. p.26

Limitations of the Study_p.29

Implications for Community Health Promotion___ p.30

\section{REFERENCES}

APPENDICES

Appendix A: Survey Cover letter

Appendix B: Health Survey 


\section{LIST OF TABLES}

4.0 Total Number of Respondents by Class Rank___ p. 18

4.1 Ages Of Respondents_p p. 19

4.2 Body Mass Indices by Number of Responses___ p. 20

4.3 Hours of Television Viewed Per Day___ p. 20

4.4 Pairwise Correlations of Body Satisfaction and Hours of T.V. Viewed Per Day__p. 21

4.5 Pairwise Correlations of Models, Celebrities, and Satisfaction

4.6 Pairwise Correlations of Hours of T.V., and

Importance of Fashion, Cosmetics, and the

Diet Industries

p. 22

4.7 Pairwise Correlations Between Satisfaction and

Social Network (Social Norm) Influences

and Self Esteem

p. 23

4.8 Number of Behaviors by Number of Responses p. 23

4.9 Body Satisfaction Compared to Exercise, Plastic

Surgery, and Eating Disorders

p. 24

4.10 Conclusions from Hypotheses p. 25 


\section{CHAPTER 1 \\ INTRODUCTION}

The relationship between the body and the mind on health can be influenced by numerous factors. The culture in which we live, religious beliefs, and relationships all affect health. While the culture, religious beliefs, and relationships have an impact on physical health, they also affect psychological health. Through messages from media, churches, and relationships with friends, families, and others, people have been taught to have particular emotional feelings about the way they feel physically. According to The

Center for Eating Disorders, they way people feel about themselves affects their behavior (Yarborough 2000).

There is a dichotomy that exists in America about one's physical body and one's perception of his/her body (or his/her body image). Body image can be influenced by four major factors, including how people feel about their bodies, how they move, how they sense their bodies, and the messages they receive about their bodies (Yarborough 2000). Today, Americans live in a culture that promotes various physical attributes that are deemed attractive. Among those attractive attributes are trim, lean, and/or muscular bodies. The dichotomy exists because we live in a time where sedentary lifestyles are the norm; and more American people than ever have access to adequate nutrition. Despite the fact that more Americans than ever are obese, unrealistic physical social norms have been created. Americans, and especially young women, often feel a sense of inadequacy when comparing themselves to these unrealistic ideals. As a result, women often feel conflicted about their own body image. Body image can be influenced by four major factors, including how people feel about their bodies, how they move, how they sense their bodies, and the messages they receive about their bodies (Yarborough 2000).

\section{STATEMENT OF RESEARCH PROBLEM}

The purpose of this study was to compare women's perceptions of body image to their behaviors. A study was needed to determine the extent to which subjective norms, 
attitudes, beliefs, Body Mass Indices (BMI) and self esteem influence body image behaviors. This research was needed because there has not been an examination these influences on body image behavior in relation to the Theory of Reasoned Action.

\section{SIGNIFICANCE OF THE PROPOSED WORK}

The significance this work stems from the prevalence of women expressing dissatisfaction with their bodies. Eating disorders, over-exercise disorders, and cosmetic surgery are some of the behaviors in which women engage. This research was particularly salient because of greater American prosperity, which affords women the luxury of attempting to change their bodies. The diet, fashion, and cosmetic industries reap significant financial reward as a result of women's negative body images. Studying women and their perceptions of their bodies can determine the extent to which these influences shape women's body image behaviors.

\section{STUDY OBJECTIVES}

The goal of this study was to determine how body mass indices, self esteem, attitudes, behaviors and subjective norms are associated with body image behaviors. The objectives of this study were to determine how body image relates to outside influences, such as cultural beliefs and relationships. In addition, outcomes of contemplating body image were assessed through the types and numbers of behaviors in which a women engaged in order to change her body.

\section{RESEARCH QUESTIONS}

1. What is the association between media and fashion and a woman's perception of her body image?

2. What is the association between social network members perception of a woman's body image and her own perception? 
3. What is the association between perceived body image and diet-related behavior?

\section{HYPOTHESES}

1. Cultural beliefs, media, and fashion shape a woman's perception of body image. Caucasian women will report higher levels of dissatisfaction with their bodies than African American women.

Women who report viewing more hours of television will be more likely to report a negative body image.

Women who feel fashion models and celebrities were very important or moderately important in shaping their perceptions of their bodies as adolescents will be more likely to report dissatisfaction with their body image.

Viewing more hours of television will be associated with greater importance of fashion, cosmetics, and the diet industry.

2. There is an association between perception of body image and social network (social norm) influences.

Those women reporting satisfaction with their bodies will perceive a more positive image about her body from her family.

The importance of a woman's body image to family, partners, friends, peers, and networks will impact diet-related, exercise-related, and cosmetic surgery behaviors. 
3. There is an association between body mass index and self esteem on behavior.

Women who report higher body mass indices and/or lower self esteem will be more likely to engage in behaviors in order to change their appearance.

Women who report the greatest body dissatisfaction will be more likely to have had an eating disorder, cosmetic surgery, or an over-exercise disorder.

4. Women who report high self esteem will report less dissatisfaction with their bodies than women who report low self esteem. 


\section{CHAPTER 2 \\ BACKGROUND}

\section{LITERATURE REVIEW}

According to Roid and Fitts, "Body image is a mental picture of the 'physical self' and includes attitudes and perceptions regarding one's physical appearance, state of health, skills, and sexuality (Roid and Fitts 1988)." In a study of body image for women who were treated for breast cancer, it was determined that there is a correlation between body image and self concept (Mock 1993, 153). According to The Center for Eating Disorders, body image influences people's feelings and behaviors. They also contend that body satisfaction is a component which influences those feelings and behaviors (The Center for Eating Disorders 2000). In addition, the influence of culture plays an integral role in the development of one's self concept. Several studies support these notions of body image.

Psychology Today surveyed its readers on body image issues in 1972, 1985 and in 1996. The authors of the survey were particularly interested in cultural messages about body size and shape, feelings about appearance, and how body image changes with age (Garner, Kearney-Cooke 1996, 55). Major findings of the most recent survey revealed: body image is influenced by moods, physical factors, and cultural factors. In addition, body dissatisfaction is increasing among both men and women. Relationships have been found to be an influence on body image, as well. Finally, the extent to which women compare themselves to models in magazines influences the degree to which they feel "resentful" or "insecure" (Psychology Today 1997, 34).

In a study of college students which explored perceptions of body image, respondents were asked to complete a self-administered questionnaire concerning factors which influence distortion of body image. In the study, factors associated with distorted body image included a desire to lose weight, the use of exercise, diet pills, vomiting, and or laxatives, and a history of rape. The authors contend distortion of body image begins when women are children, when they learn to favor more slender body shapes (Stuhldreher and Ryan 1999, 9). 
In one study, focus groups were used in order to study "social comparison" as it related to advertisements for clothing and beauty products. The researches looked at whether participants compared their bodies to others, and in particular, models in advertisements. One of the key findings in this study was that women who reported high self esteem reported less social comparison to the models, and reported less dissatisfaction with their own appearance than women who reported low self esteem. In fact, participants in this study reported they disliked apparel and beauty product advertising due to the "unrealistically high aesthetic standard" these advertisements perpetuated (Lennon, Lillethun, and Buckland 1999, 379).

In another study of the effects of the media on body image, 548 girls in fifth through twelfth grades were surveyed to determine the extent to which media influences weight concerns, weight control and weight loss behaviors, and perceptions of body shape and size. The study measured the perceived influence of fashion magazines, body dissatisfaction, body shape, dieting to lose weight and engaging in an exercise program. The results indicated $69 \%$ of the girls felt magazine pictures influenced their idea of the "perfect body shape," and 47\% wanted to lose weight because of viewing pictures in magazines (Brown University Child and Adolescent Behavior Letter 1999).

In an article entitled "The Effects of Viewing Same-Gender Photographic Models on Body Esteem," reports of a study conducted on photographic images and their influence on body esteem were detailed. According to the study, women scored significantly lower on body esteem scales than men. In addition, there was a significant decrease in body esteem after viewing photographs of same-gender models (Grogan, Williams, and Conner 1996, 569) for both women and men. People of both genders compared their bodies unfavorably after viewing images of models (Grogan, Williams, and Conner 1996, 574).

Studies have been conducted in order to demonstrate the effects of self esteem on body image behaviors among a variety of ethnic groups. In a study of Mexican American 
women, lower levels of self esteem, BMI, and body dissatisfaction were predicative of higher levels of bulimia and anorexia behaviors (Joiner and Kashubeck 1996, 419). In a study of eating disorders among African American, Asian Americans, and Caucasians, behaviors and attitudes were assessed. Caucasians reported greater levels of disordered eating and greater body dissatisfaction than Asian Americans and African Americans. Additionally, low self esteem and high public self-consciousness were associated with greater levels of disordered eating and body dissatisfaction (Henderson 1995, 18). Finally, in an article entitled "Gender and Ethnic Differences in the Relationship Between Body Esteem and Self Esteem," changes in these variables were assessed over time. Results of the study indicated Caucasian women are more likely to develop bulimia than men or women from either of the other ethnic groups because it appears Caucasian women are more concerned with appearance, body shape, and weight (Henriques and Calhoun 1999, 1). It also appears Caucasian women are more likely to change their appearance in order to improve their self esteem (Henriques and Calhoun1999, 7).

A number of studies have made comparisons between Caucasian and African American women. Issues of self concept, body image, and/or eating habits have been explored by Smith et al.(1999), le Grange, et al. (1995), Wilfley, et al. (1995), and Powell, et al. (1994). Primarily, these studies have been concerned with exploring how women's attitudes vary by race or ethnicity.

The Coronary Artery Risk Development in Young Adults (CARDIA) Study has provided an examination of body image with Caucasian and African American men and women (Smith, et al. 1999). Smith writes that their population consisted of 1,837 men (45\% of whom were African American), and 1,895 women (51\% of whom were African American). Significant results of the study included information on appearance, body size, obesity, and dissatisfaction with their bodies. It was concluded that African American and Caucasian women were, “....similarly dissatisfied with size and appearance (Smith, et al. 1999)." But, after adjusting for age, body mass index, and education, African American women were more satisfied with "dimensions" than Caucasian women. Obesity was correlated with body dissatisfaction in all gender and ethnicity groups. 
The following studies relate to body image and eating behaviors. The purpose of the research by le Grange, Telch, and Agras (1995) was to demonstrate whether a difference exists between the eating disorders in Caucasians and minorities. Participants in their study participated in the Structured Clinical Interview for the DSM-III-R, the Eating Disorders Examination-Questionnaire, and the Rosenberg Self-Esteem Scale in order to determine eating disorder pathology and psychopathology. The results of their study showed, “...no significant differences between the minority and Caucasian subjects' responses on the eating disorder and general psychopathology indices" but, weight concern was highest for Caucasian bulimics (le Grange, et al. 1997, 291). The limits of the study, however, were that the population consisted of $73 \%$ Caucasian, $15 \%$ Hispanic, 7\% African American, 3\% Asian American, and 1\% American Indian. Of the 149 women who participated in the study, 109 were Caucasian and only 40 were minorities. The results of this study are limited by the small sample size of the minority subjects.

In a study of eating disturbance and body image, Wilfley, et al. (1995) examined the differences in eating disorders and body dissatisfaction between middleaged African American and Caucasian women. The authors investigated factors that may contribute to dissatisfaction with body image (Wilfley, et al. 1995, 377). Some of these factors included: degree of overweight, socioeconomic status, criticism about their weight, comparing themselves to others, and social pressures (Wilfley, et al. 1995, 378). Their 271 black participants and 267 white participants responded to a questionnaire on demographics, psychosocial questionnaires to determine eating habits and attitudes, and had their BMI calculated (Wilfley, et al. 1995, 379). Results of the study concluded that black and white women had "comparable levels of eating disturbance, ... until we controlled for BMI (Wilfley, et al. 1996, 384)." With respect to controlling for overweight, white women expressed more dissatisfaction than black women. The authors speculate black women "...may live in an environment that is more permissive of overweight..." and that may be the reason for lower body dissatisfaction than for white women (Wilfley, et al. 1996, 386). The authors also contend that comparing middle-age 
women to a college-age sample may be spurious, however, because as women age, they are subject to weight change, pregnancy, or other biological factors (Wilfley, et al. 1996, $385)$.

A study involving 202 college students at James Madison University was entitled "Racial Differences in Women's Desires to be Thin." The authors used both female and male subjects for their population. The female participants answered a questionnaire on attitudes about weight, and were asked to choose silhouettes which they considered the ideal body size, their current body size, and which they thought would be most attractive to a man (Powell and Kahn 1995, 192). The results of this study showed white women chose thinner ideal body sizes than black women chose; and white women demonstrated a wider discrepancy between their ideal and their current silhouette than black women. In addition, white women expressed greater social pressure to be thin, and a greater concern with weight and dieting than black women. The authors conclude, “...the black culture is more accepting than white culture of women larger than society's extremely thin ideal, and places less emphasis on thinness when assessing social desirability (Powell and Kahn 1994, 194).

Modest information exists on the rates of cosmetic surgery among minorities in the United States. In an anthology edited by Weitz entitled The Politics of Women's Bodies, Eugenia Kaw quotes the American Society of Plastic and Reconstructive Surgeons by stating that $14 \%$ of cosmetic surgeries in 1994 were performed on Latinos, African Americans, and Asian Americans (Kaw and Weitz 1998, 167). Kaw contends surgeries are "racially specific (Kaw and Weitz 1998, 167)." Kaw argues Asian American women decide to undergo cosmetic surgery in, “... an attempt to escape persisting racial prejudice that correlates their stereotyped genetic physical features... with negative behavioral characteristics, such as passivity, dullness, and a lack of sociability (Kaw and Weitz 1998, 168).”

Eugenia Kaw constructed a survey in which she focused on, “...the conscious or unconscious manipulation of gender and racial stereotypes, the American medical system, along with the ...society of which it is a part, influences Asian American women to alter 
their features (Kaw and Weitz 1998, 168)." Her study consisted of open-ended key informant interviews with Asian American women and an examination of the medical files of cosmetic surgeons in the San Francisco area. One of the most significant results illustrated in the interviews was that the cosmetic surgeons used medical terms in order to define ethnic features as problematic

(Kaw and Weitz 1998, 174).

It appears that there is a great deal of cultural variability in body image. Whether the variability is due, in part, to geographic location or to cultural factors within those locales, the significance of the literature review demonstrates the variance in body image through physical effects and attributes, and through punitive behaviors done in order to change one's body.

\section{THEORETICAL FRAMEWORK}

This study utilized components of the Theory of Reasoned Action. According to Glanz, et al., the Theory of Reasoned Action is, “...concerned with individual motivational factors as determinants of the likelihood of performing a specific behavior (Glanz, et al. 1997, 95)." The theory demonstrates how attitude and social norms influence behavioral intentions and then behavior. In addition, the theory postulates that attitudes, subjective norms, and behavioral control affect behaviors. External variables to the theory include age, gender, ethnicity, and culture, which, in turn, may be related to beliefs, which, in turn, affect behavioral control, behavioral intentions, and then behavior.

The Theory of Reasoned Action, ultimately, was used to examine behavioral intentions as influences on body image behaviors. It's components showed how behavior was a result of behavioral intentions (Glanz, et al. 1997, 86). Behavioral control and normative measures occured on a scale of how likely or unlikely a behavior is to take place (Glanz, et al. 1997, 91). Behaviors and outcomes were determined by asking the respondents to respond to several questions that determined whether they have done something detrimental to their bodies in a desire to look a particular way. Subjective 
norms were determined by asking whether family, friends, or others approve of disapprove of the behaviors in which they have engaged in attempts to change their bodies. The subjective norm component of the Theory of Reasoned Action influence the hypothesis, "There is an association between perception of body image and social network influences."

Finally, social support and subjective norms were appraised to determine respondents' networks, and the degree to which those networks are supportive. Glanz, et al. (1997) write that social support has a "stress-buffering" effect, which insulates people to some degree. They continue, “...social support will strengthen in its positive effects on adjustment and physical well-being as a stressor becomes more intense or persistent (Glanz, et al. 1997, 125)." In evaluating subjective norms, the respondents' answers were used to demonstrate the effects of relationships on their body image and behavior. They were asked to determine the extent to which family, partners, friends, and peers affect their body image. 


\section{CHAPTER 3}

\section{RESEARCH METHODS}

\section{RESEARCH DESIGN}

This study was a non-experimental cross sectional study of female students at West Virginia University. Its purpose was to examine attitudes and behaviors in the context of naturally occurring phenomena. Because it was a cross sectional design, data was collected at one point in time through one questionnaire. The purpose was to show the relationship between the variables of self esteem, BMI, subjective norms and attitudes toward body image behaviors.

\section{STUDY POPULATION}

The population consisted of female students at West Virginia University. The total student population at West Virginia University for Spring 2000 was approximately 22,000. There were approximately 11,000 female students at the time of this research. Female students were systematically, randomly selected by choosing the first five female names on every other page of the 1999-2000 Campus Directory until 400 names were selected. Women were notified of their selection in the study through a letter mailed to their address listed in the Campus Directory.

\section{DATA COLLECTION}

The method of data collection was a mailed questionnaire, with a self-addressed stamped reply envelope. This questionnaire was mailed to the participants once during the week of April 27, 2000. There were no follow-up mailings to remind the women to return their surveys due to time constraints. Generally, questions were answered on a Likert Scale for ordinal measures in which respondents were asked the degree to which the agreed or disagreed with statements about body image. In addition, questions such as 
ethnicity were partially closed-ended, and ordered questions were used to find ordinal information. Measures of overall body image were examined by determining behaviors, subjective norms, self-esteem, attitudes, beliefs, and body mass index from the questionnaire. The questions dealing with self esteem were adapted from the "Rosenberg Self-Esteem Questionnaire (1965);" and the remainder of the questionnaire was adapted from "The Survey on Body Image" from Psychology Today (1996).

Because women could learn to value particular features through observing their family, friends, or what is portrayed in the media (through television, movies, and print advertisements), women were asked to indicate on a Likert scale the degree to which family, friends, and the media influence feelings about their bodies, and the degree to which those influences cause them to engage in particular behaviors (such as eating behaviors, exercising, and purchasing cosmetics or particular clothing). Media effects on mass society and culture were also be explored. Specifically, the extent to which the media influences body image was explored. Media effects were determined through the influence of media effects on behavior.

\section{ANALYSIS}

Correlations were made for cross sectional data and ordinal and continuous scales. Spearman correlational analysis was used for ordinal scales, and Pearson correlational analysis was used for continuous data. The independent variables included: attitudes and beliefs, subjective norms and social network influences. The dependent variables included eating disorders, over-exercise disorders, and/or cosmetic surgery behaviors.

The following demonstrates the relationship between the factors addressed and their influence on behaviors. Subjective norms and attitudes are direct influences on body mass index, body image and self esteem. Body Mass Index, body image (satisfaction), and self esteem are direct influence on behaviors (dieting, exercise, cosmetic surgery, etc.). Behavior is equal to the sum of the influences of subjective norms and attitudes on body image (satisfaction). 
The following demonstrates how various questions appearing on the questionnaire were operationalized. Each category of questions was grouped in order to form a scale, by which other variables could be compared.

Questions concerning cultural beliefs, media, television and/or fashion and their influences on body image include: Qs 22, 23, 41, 42, 43 and 63. Rated Very Important, Moderately Important, Somewhat Important, Somewhat Unimportant, to Very Unimportant included: \#22: Importance of fashion magazine models, and \#23: Importance of movie or television celebrities. Rated Always, Very Often, Often, Rarely, to Never included: \#41: How often do you compare yourself to models in magazines?; \#42: Do you carefully study the shapes of models in magazines?; and \#43: Do you buy cosmetics or personal grooming products because of models?

Questions concerning social networks or social norms and their influences on body image include: Qs 8, 9, 11, 12, 16, 24, 25, 26 and 59.

Rated from Very Important, Moderately Important, Somewhat Important, Somewhat Unimportant, Moderately Unimportant, to Very Unimportant included: \#8: Importance of being around someone who is critical of your body, \#9: Importance of living up to your family's standards of looks, \#11: Importance of being teased about your body when you were younger, \#12: Importance of a partner's opinion of your appearance, \#16: Importance of compliments from others on your appearance, \#24: Importance of how your mother feels about your body, \#25: Importance of how your father feels about your body, and \#26: Importance of how your friends feel about your body.

Question \#59: People who are important to me (parents, siblings, girlfriends, boyfriends) think my appearance is just right, was ranked from Strongly Agree, Agree, Disagree, to Strongly Disagree.

Questions concerning behavior include: Qs 4, 5, 7, 10, 13, 14, 15, 17, 18, 20, 21, $27,28,29,30,31,32,33,34,35,36,37,38,38 \mathrm{~A}, 39,40$, and 63.

Question \#4: On average, in the past year, how often have you exercised per week?; was ranked by Never, 1 Time Per Week, 2-3 Times Per Week, 4-5 Times Per Week, 5-6 Times Per Week, or 6-7 Times Per Week. 
Question \#5: On average, how long do you exercise each time?; was ranked by 1-9 Minutes, 10-19 Minutes, 20-29 Minutes, 30-59 Minutes, 1-2 Hours, to More than 2 Hours.

Questions 7-21 were ranked by order of Very Important, Moderately Important, Somewhat Important, Somewhat Unimportant, Moderately Unimportant, Very Unimportant.

\#7: Importance of not getting regular exercise \#10: Importance of eating fattening foods \#13: Importance of gaining weight \#14: Importance of regular exercise \#15: Importance of losing weight \#17: Importance of using cosmetics or personal grooming products \#18: Importance of wearing flattering clothing \#20: Importance of eating low-fat foods \#21: Importance of plastic surgery 
Questions 27-34 were ranked from Never, Less than once a month, About once a week, to Two or more times a week.

\#27: Use of diet pills

\#28: Use of laxatives

\#29: Use of diuretics

\#30: Use of exercise for weight loss

\#31: Use of self-induced vomiting

\#32: Use of extreme caloric restriction (less than 500 calories/day)

\#33: Use of moderate caloric restriction

\#34: Change in types of food eaten

Questions 35-40 were answered by No or Yes.

\#35: Have you ever dieted to lose weight?

\#36: Have you ever followed a liquid-formula diet to lose weight?

\#37: Have you ever followed a commercial weight-loss program to lose weight?

\#38: Has anyone ever told you that you have an eating disorder?

\#38A: If yes, have you ever received treatment?

\#39: Do you intend to try to lose weight within the next 6 months?

\#40: Have you ever had plastic (cosmetic) surgery?

Question \#63: On average, how many hours of television do you watch every day?; asked for total hours.

Questions concerning self esteem include: Qs \#44-55. These questions were taken directly from the Rosenberg Self Esteem Scale. These were ranked from Strongly agree, Agree, Disagree, to Strongly disagree.

\#44: On the whole, I am satisfied with myself.

\#45: At times, I think I am no good.

\#46: I feel that I have a number of good qualities.

\#47: On the whole, I am satisfied with myself.

\#48: At times, I think I am no good.

\#49: I am able to do things as well as other people. 
\#50: I feel I do not have much to be proud of.

\#51: I certainly feel useless at times.

\#52: I feel I'm a person of worth, at least on an equal plane with others.

\#53: I wish I could have more respect for myself.

\#54: All in all, I am inclined to feel that I am a failure.

\#55: I take a positive attitude toward myself.

Questions concerning body satisfaction include: Qs 6, 56, and 58.

Question \#6: When you look at your body in the mirror, how satisfied do you feel about what you see?; was ranked from Very satisfied, Somewhat satisfied, Neutral, Somewhat dissatisfied, to Very dissatisfied.

Questions \#56: On the whole, I am satisfied with my body, and \#58: I feel that I have a number of good physical qualities, were ranked from Strongly agree, Agree, Disagree, to Strongly disagree.

Ethnicity (Caucasian/Non-Hispanic, Hispanic/Latina, African American, Asian Pacific Islander, Native American, Multiracial/Other)is determined by question 60. Body mass indices are determined by questions 61(height) and 62 (weight). Gender (Are you female or male?) is determined on question 1. Class standing (freshman, sophomore, junior, senior, graduate student, no longer enrolled, other) is determined on question 2. Age is determined on question 3. 


\section{CHAPTER 4}

\section{RESULTS}

\section{CHARACTERISTICS OF SAMPLE}

Four hundred surveys were mailed to female students listed in the West Virginia University Student Directory. Of those mailed, 45 were returned by the Post Office as "undeliverable." A total of 114 completed surveys were returned, but one was discarded because the respondent was a male. Therefore, the response rate for this survey was 113 out of 355 , or $31.8 \%$.

The following tables illustrate the distribution of characteristics of the respondents.

\begin{tabular}{lrr}
\hline \multicolumn{3}{l}{ TABLE 4.0 TOTAL NUMBER OF RESPONDENTS BY CLASS RANK } \\
\hline Class & Total \# & \% of responses \\
& & \\
Freshman & 8 & 7.3 \\
Sophomore & 11 & 10.1 \\
Junior & 11 & 10.1 \\
Senior & 23 & 21.1 \\
Graduate Student & 39 & 35.8 \\
No longer Enrolled & 17 & 15.6 \\
Other & 0 & 0 \\
& & \\
Total Responses & 109 & 96.5 \\
\hline
\end{tabular}

The total number of responses (109) for Question \#2 Class Rank was divided by the number of responses for each category of Class. The largest percentage of students $(35.8 \%)$ who returned surveys indicated they were graduate students at the time of the survey. 


\begin{tabular}{lrr}
\hline \multicolumn{3}{c}{ TABLE 4.1 AGES OF RESPONDENTS } \\
\hline & & \\
AGES & TOTAL \# & $\%$ of responses \\
& & \\
$\mathbf{1 8 - 2 0}$ & 24 & 22.6 \\
$\mathbf{2 1 - 2 3}$ & 32 & 30.2 \\
$\mathbf{2 4 - 2 6}$ & 13 & 12.3 \\
$\mathbf{2 7 - 2 9}$ & 10 & 9.4 \\
$\mathbf{3 0 - 3 9}$ & 7 & 6.6 \\
$\mathbf{4 0 - 4 9}$ & 15 & 14.2 \\
$\mathbf{5 0 - 5 6}$ & 5 & 4.7 \\
& & \\
Total Responses & 106 & 93.8 \\
\hline
\end{tabular}

The largest percentage of students who returned surveys were between the ages of 21 and 23 at the time of the survey (30.2\%). The mean age of participants was 27.8 years.

\begin{tabular}{lrr}
\hline TABLE 4.2 BODY MASS INDICES BY NUMBER OF RESPONSES \\
\hline & & \\
BMI & TOTAL NUMBER \% of responses \\
$\mathbf{1 7 . 0 - 2 0 . 0}$ & 17 & 15.5 \\
$\mathbf{2 0 . 1 - 2 1 . 9}$ & 32 & 29.1 \\
$\mathbf{2 2 . 0 - 2 3 . 9}$ & 14 & 12.7 \\
$\mathbf{2 4 . 0 - 2 5 . 9}$ & 20 & 18.2 \\
$\mathbf{2 6 . 0 - 2 7 . 9}$ & 10 & 9.1 \\
$\mathbf{2 8 . 0 - 2 9 . 9}$ & 10 & 9.1 \\
$\mathbf{3 0 . 0 - 3 6 . 0}$ & 7 & 6.4 \\
& & \\
Total Responses & 110 & 97.3 \\
\hline
\end{tabular}

Body Mass Indices were calculated by dividing the respondent's weight in kilograms by the height squared in meters. 110 responses for Body Mass Index resulted from respondents answering both questions 61 and 62 for height and weight. The largest percentage of respondents (29.1\%) had BMI's of 20.1-21.9 at the time of the survey. 


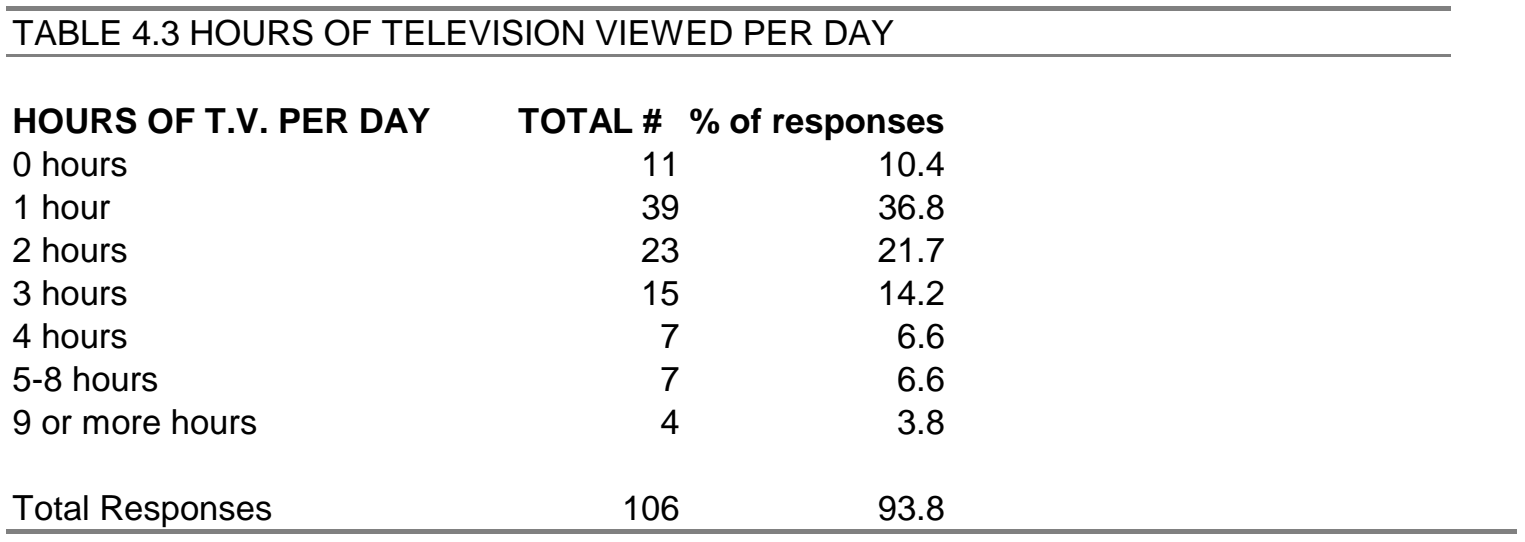

A total of 106 respondents answered Question \# 63, which asked how many hours of television they watched per day. The largest percentage of respondents (36.8\%) indicated they watched television 1 hour per day.

\section{FINDINGS/THEMES}

The following findings indicate results gathered from the respondents' questionnaires and their association to the hypotheses.

Hypothesis 1: Cultural beliefs, media, and fashion shape a woman's perception of body image.

\section{A. Caucasian women will report higher levels of dissatisfaction with their bodies than African American women.}

This hypothesis could not be addressed in the study because only 1 African American woman returned a survey. While there is ample evidence to suggest African American 
women report higher levels of body satisfaction than Caucasian women (Henderson (1995), Smith et. al (1999), le Grange et. al (1995), Wilflely et. al (1995), and Powell et. al (1994), the hypothesis "Caucasian women will report higher levels of dissatisfaction with their bodies than African American women" could not be tested.

\section{B. Women who report viewing more hours of television will be more likely to report negative body image (or dissatisfaction).}

There was no relationship between hours of television viewed per day and satisfaction with one's body or body image. Question \#6 ("When you look in the mirror, how satisfied do you feel about what you see?") was compared to Question \# 63 ("How many hours of television do you watch per day?”) for a P value of .7179. Question \# 56 (“On the whole, I am satisfied with my body") was compared to Question \#63 (hours of television) for a P value of .2094. Question \#58 ("I feel that I have a number of good physical qualities) was also compared to Question \#63 (hours of television) for a P value of .5555 .

\begin{tabular}{llc}
\hline TABLE 4.4 PAIRWISE CORRELATION OF BODY SATISFACTION AND & \\
\hline HOURS OF TELEVISION VIEWED PER DAY \\
Hours of Television Viewed Per Day
\end{tabular}




\section{C. Women who feel fashion models and celebrities were very important or moderately important in shaping their perceptions of their bodies will be more}

\section{likely to report dissatisfaction with their body image.}

There was a relationship between the influence of fashion models and celebrities in shaping a woman's body image and her level of satisfaction with her body. Significant findings were found in the comparison of the following questions. Question \#22 (importance of "Fashion magazine models") was compared to Question \#56 ("On the whole, I am satisfied with my body") for a P value of .034. Question \#22 was then compared to Question \# 58 ("I feel I have a number of good physical qualities") rendering a P value of .037. Also, Question \#23 (importance of "Movie or television celebrities") was compared to Questions \#6 ("When you look in the mirror, how satisfied do you feel about what you see?") with a P value of .002. Question \#23 was then compared to Question \#56 demonstrating a P value of .013. Finally, Question \#23 was compared to Question 58 with the resulting P value of .001. Question \#41 ("How often do you compare yourself to models in magazines?") was compared to Questions \#6 (P value .007 ) and \#56 (P value .041). Finally, Question \#42 ("Do you carefully study the shapes of models in magazines?") was compared to Questions \#6 (P value .0004) and to \#56 (P value .015).

There was a negative relationship between the variables. When women indicate fashion models and celebrities are or were important in shaping the way they feel about their bodies, their level of satisfaction with their bodies decreases. The most significant 
relationship between variables is with Question \#42 ("How carefully do you study the shapes of models in magazines?") and Question \# 6 ("When you look in the mirror, how satisfied do you feel with what you see?") with a P value of .0004.

TABLE 4.5 PAIRWISE CORRELATIONS OF MODELS, CELEBRITIES, AND SATISFACTION

$\begin{array}{ll}\text { Correlation } & \text { Significant } \\ \text { Coefficient } & \text { Probability }\end{array}$

Importance of models/celebrities Satisfaction with Body (Q's 6,42,56)

$\begin{array}{lll}\text { Importance of fashion magazine models. } & -.1995 & .0342 \\ \text { Importance of fashion magazine models. } & -.1962 & .0373 \\ \text { Importance of movie or t.v. celebrities. } & -.2913 & .0019 \\ \text { Importance of movie or t.v. celebrities. } & -.2361 & .0126 \\ \text { Importance of movie or t.v. celebrities. } & -.2996 & .0014 \\ \text { How often do you compare yourself to models in magazines? } & -.2533 & .0071 \\ \text { How often do you compare yourself to models in magazines? } & -.1934 & .041 \\ \text { Do you carefully study the shapes of models in magazines? } & -.3292 & .0004 \\ \text { Do you carefully study the shapes of models in magazines? } & -.2287 & .0153\end{array}$

\section{D. Viewing more hours of television will be associated with greater importance of fashion, cosmetics, and the diet industry.}

There was no relationship between viewing more hours of television and the perceived importance of fashion, cosmetics and the diet industry. Question \#63 ("How many hours of television do you watch per day?") was compared to Questions \# 22 (for a P value of .920), Q\# 23 (P value .868), Q\# 41 (P value .166), Q\# 42 (P value .907), and Q\# 43 (P value .494). 


\begin{tabular}{|c|c|c|}
\hline TABLE 4.6 PAIRWISE CORRELATION & OF HOURS C & PF TELEVISION \\
\hline AND IMPORTANCE OF FASHION, CO & AETICS, AND & $\begin{array}{l}\text { THE DIET INDUSTRY } \\
\text { Hours of t.v. viewed per day }\end{array}$ \\
\hline Importance of models or celebrities & $\begin{array}{l}\text { Correlation } \\
\text { Coefficient }\end{array}$ & $\begin{array}{l}\text { Significant } \\
\text { Probability }\end{array}$ \\
\hline Importance of fashion magazine models. & -.0096 & .9205 \\
\hline Importance of movie or t.v. celebrities. & -.0161 & .8683 \\
\hline $\begin{array}{l}\text { How often do you compare yourself to models in } \\
\text { magazines? }\end{array}$ & -.1335 & .1665 \\
\hline $\begin{array}{l}\text { Do you carefully study the shapes of models in } \\
\text { magazines? }\end{array}$ & .0112 & .9077 \\
\hline $\begin{array}{l}\text { Do you buy cosmetics or personal grooming } \\
\text { products because of models? }\end{array}$ & -.0662 & .4941 \\
\hline
\end{tabular}

Hypothesis 2: There is an association between perception of body image and social network (social norm) influences.

\section{A. Those women reporting satisfaction with their bodies will perceive a more positive image about her body from her family.}

There is a relationship between Question \# 6 (how satisfied a woman feels when she looks in the mirror) and Question \# 59 ("People who are important to me [parents, siblings, girlfriends, boyfriends] think my appearance is just right"). It is especially noteworthy that Question \#59 elicited more of a significant response than by comparing satisfaction with either mom, dad, partner, or friends singularly to satisfaction. 


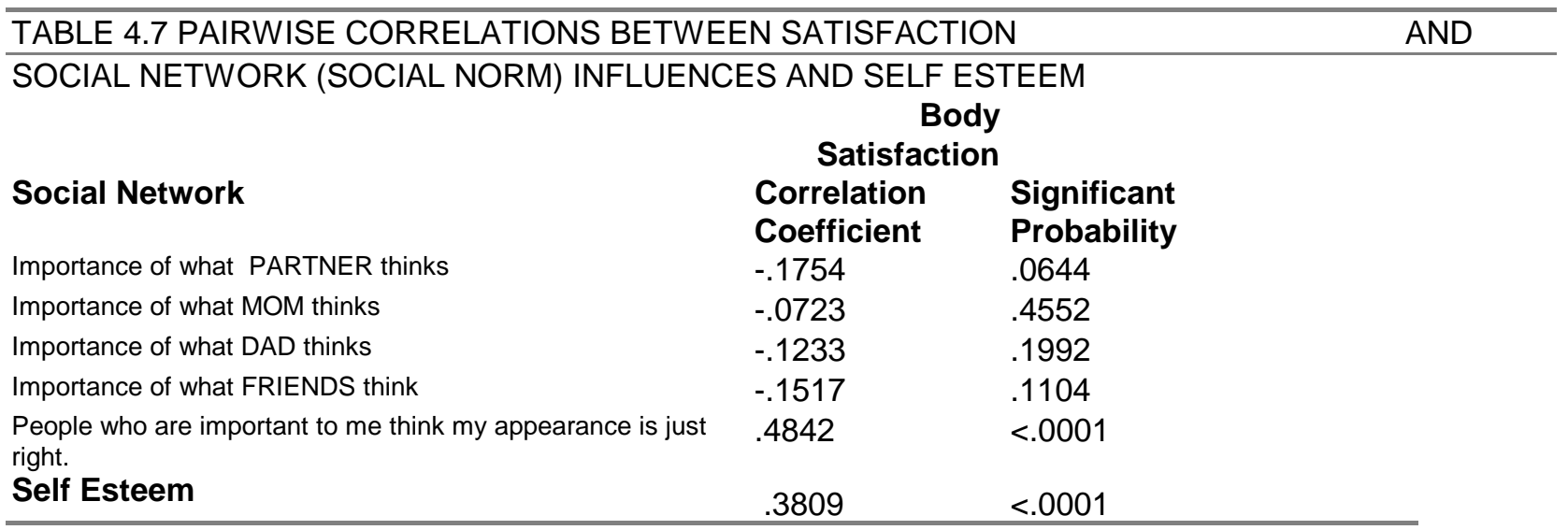

2. B. The importance of a woman's body image to family, friends, partners, peers and networks will impact diet-related, exercise-related, and cosmetic surgery behaviors.

There is a significant relationship between the importance of social networks and behaviors. Social network questions were grouped with each other; and similarly, all behavior questions were grouped. When grouping the influences of social networks (family, friends, partners, and peers) and making a comparison to the group of body image behaviors (including exercise, laxative use, diuretic use, vomiting, caloric restriction, changes in types of food eaten, liquid diet, and following a commercial program for weight loss), there was a significant probability of .0006. It was interesting to note the following behaviors concerning eating disorders, intentions to lose weight, and plastic surgery. A total of 7 respondents reported having an eating disorder, while only one of those respondents received treatment for the eating disorder. In addition, $70.1 \%$ of all 
respondents intended to lose weight within the next 6 months. Finally, only 2 of the

respondents ever had plastic surgery.

\begin{tabular}{crrr}
\hline TABLE 4.8 NUMBER OF BEHAVIORS BY NUMBER OF RESPONSES & \\
\hline Has anyone ever told you that you have an & \#Yes: & \#No: & $\%$ Yes: \\
eating disorder? & 7 & 106 & 6.2 \\
Have you ever received treatment? & 1 & 6 & .88 \\
Do you intend to lose weight in the next 6 months? & 80 & 33 & 70.1 \\
Have you ever had plastic surgery? & 2 & 111 & 1.8
\end{tabular}

\section{Hypothesis 3: There is an association between body mass index and self esteem on} behavior.

\section{A. Women who report higher Body Mass Indices and/or lower self esteem will be more likely to engage in behaviors in order to change their appearance.}

There was a significant association between self esteem and behavior. However, there was no relationship between BMI and behavior. When combining the types of behaviors listed in Hypothesis 2 B (exercise, laxative use, diuretic use, vomiting, caloric restriction, changes in types of food eaten, liquid diet, and following a commercial weight loss program) and combining the results of the Rosenberg Self Esteem Score (Questions 4455), the $P$ value was .0008 , indicating significant behaviors by self esteem (data shown in Table 4.7). The lower the self esteem, the more behaviors a woman engaged in to change her appearance. Consequently, the higher the self esteem, the lower the number of appearance-changing behaviors. When comparing BMI to behaviors (those listed above), there was a $\mathrm{P}$ value of .3413 , indicating no relationship between BMI and behaviors. (This data is not shown in table.) 
Other significant findings from this sample included the distribution of BMI's reported.

Fully $15.5 \%$ of respondents were in the 17.0 to 20.0 BMI range, which is classified as "underweight" (Hoeger and Hoeger 1997, 67). In addition, 60.0\% of respondents fell within the "acceptable" range. Further, $18.2 \%$ of respondents were classified as“overweight," while 15.5\% were considered "obese" (Hoeger and Hoeger 1997, 67).

Those respondents who were classified as underweight, overweight, or obese have a moderate to high disease risk (Hoeger and Hoeger 1997, 67). It is especially noteworthy that $70.1 \%$ of all respondents responded "yes" when asked if they intended to lose weight within the next six months, while it appears that $33.7 \%$ of respondents are classified as overweight or obese.

\section{B. Women who report the greatest body dissatisfaction will be more likely to have}

\section{had an eating disorder, cosmetic surgery, or an over-exercise disorder.}

There was no association between exercise or cosmetic surgery and body satisfaction.

However, there was a significant association between eating disorders and body

satisfaction (P value .0012). Reporting an eating disorder was strongly associated with body dissatisfaction.

TABLE 4.9 BODY SATISFACTION COMPARED TO EXERCISE, PLASTIC SURGERY, AND EATING DISORDERS

\section{Behaviors}

\section{Body Satisfaction}

When you look at your body in the mirror, how satisfied do you feel about what you see?

When you look at your body in the mirror, how

satisfied do you feel about what you see?

When you look at your body in the mirror, how

satisfied do you feel about what you see?

When you look at your body in the mirror, how

satisfied do you feel about what you see?

\section{Significant}

Probability

.1693

.9994

.0012

.5922 


\section{Hypothesis 4: Women who report high self esteem will report less dissatisfaction with their bodies than women who report low self esteem.}

There is an association between self esteem and body satisfaction. When the Rosenberg Self Esteem questions (\#44-55) were compared to the questions concerning

body satisfaction (\#6, 56, and 58), a significant probability of .001 was gained. (This data is not shown in table.) Therefore, women who report higher self esteem also report higher body satisfaction.

In conclusion, the results from testing the hypotheses are as follows.

TABLE 4.10 CONCLUSIONS FROM HYPOTHESES

$\begin{array}{lll}\text { HYPOTHESIS } & \text { WAS THERE A RELATIONSHIP BETW } \\ \text { Hypothesis 1A } & \text { Race \& satisfaction } & \text { Not Tested } \\ \text { Hypothesis 1B } & \text { T.V. \& satisfaction } & \text { No } \\ \text { Hypothesis 1C } & \text { Models \& satisfaction } & \text { Yes } \\ \text { Hypothesis 1D } & \text { T.V. \& fashion, etc. } & \text { No } \\ \text { Hypothesis 2A } & \text { Satisfaction \& family } & \text { Yes } \\ \text { Hypothesis 2B } & \text { Networks \& behavior } & \text { Yes } \\ \text { Hypothesis 3A } & \text { Self Esteem \& behavior } & \text { Yes } \\ \text { Hypothesis 3A } & \text { BMI and behavior } & \text { No } \\ \text { Hypothesis 3B } & \text { Satisfaction \& behavior } & \text { No } \\ \text { Hypothesis 4 } & \text { Self Esteem \& Satisfaction } & \text { Yes }\end{array}$




\section{CHAPTER 5}

\section{DISCUSSION}

\section{MAJOR FINDINGS}

The major findings in this survey were divided into the following categories: BMI, television viewing, body satisfaction, social norms, self esteem and their associations with body image behaviors.

One of the hypotheses concerning BMI predicted that women who reported higher BMI's would be more likely to engage in behaviors in order to change their appearance. Although there was nothing in the literature to support this hypothesis, it seemed reasonable that behaviors might be affected by a woman's BMI. These behaviors included dieting, purchasing cosmetics or fashions, or having an eating disorder. This survey demonstrated there was no association between BMI and appearance changing behaviors. Women with high BMI's were no more or less likely to engage in appearance changing behaviors than women with lower BMI's.

Several studies have focused on media effects, or particularly the effects of television, on women (Lennon et. al (1999), Brown University (1999), and Grogan et. al (1996). One of the major findings in the study by Lennon et. al (1999) was that women who reported high self esteem reported less social comparison to models, and reported less dissatisfaction with their appearance than women who reported low self esteem (Lennon, et. al 1999). In the Brown University study of 548 girls, results indicated 69\% felt magazine pictures influenced their idea of the "perfect body shape (Brown University, 1999)." In the Grogan et. al (1996) study it was determined women compare themselves "unfavorably" after looking at images of models (Grogan et. al 1996, 574). 
Evidence supports the notion that cultural beliefs, media, and fashion shape a woman's perception of body image. While there was no relationship between hours of television viewed and satisfaction with one's body, and no relationship between hours of television viewed and the importance of fashion, cosmetics, and the diet industry, there were relationships demonstrated between women comparing themselves to fashion models and/or celebrities and their own body satisfaction. Every variable comparing satisfaction to models or celebrities showed a high negative correlation. When women reported they compared themselves to models and celebrities or studied the shapes of models or celebrities, their own level of body satisfaction was lower.

Body satisfaction was a key component of body image and behaviors. Satisfaction could be successfully compared to behaviors of those Caucasian women who responded. There was a strong association between body satisfaction and eating disorders. Reporting an eating disorder was associated with body dissatisfaction. There was no relationship demonstrated between exercise or cosmetic surgery and body satisfaction, however.

Social norms or social networks had a great deal of influence on women and their body image. As the Theory of Reasoned action suggests, subjective norms and attitudes influence self esteem, affect behaviors. When comparing the influence of family, friends, partners, and/or peers to behaviors, a significant relationship was demonstrated. The importance of a woman's body image to family, friends, partners and peers does, indeed, impact diet-related, exercise-related, and cosmetic surgery behaviors. The greatest relationship was demonstrated by body satisfaction and what important people (parents, siblings, girlfriends, boyfriends) thought about a woman's appearance, than by comparing satisfaction to either parents, siblings, or friends singularly. 
Finally, self esteem was demonstrated as a major factor in women's body image. There was a significant relationship between low self esteem and engaging in appearancechanging behaviors. In addition, women who reported higher self esteem engaged also reported greater body satisfaction.

It appears that components of the Theory of Reasoned Action supported the generation of the hypotheses. Subjective norms and attitudes were, indeed, influential on Body Mass Index, body image, and self esteem, which, in turn, were influences on behaviors.

\section{LIMITATIONS OF THE STUDY}

Limitations of the study included resources, timing, sampling, and ethnic diversity. The study was somewhat limited by mailing only 400 surveys to female students. While those who received the survey received a postage paid envelope to return the completed survey, only $31.8 \%$ of the responses were viable. A total of 45 surveys were returned as "undeliverable." The survey was mailed during the last week of April 2000, just one week before students finished the spring semester. The response rate was probably lower because students either moved or were engaged in studying for finals during the survey period. There was also not a follow-up reminder was not sent to the students, which may have also contributed to a lower response rate.

Sampling was another limitation to the study. While a random sample of female students seemed appropriate, only two minority students responded to the survey. Therefore, ethnicity could not be associated with body image behaviors. In particular, an 
association between body satisfaction and African American women versus satisfaction among Caucasian women could not be determined. Rather than using a systematic, random sample, minority participants could have been oversampled by going recruiting through minority sororities on campus. Some of these limitations could have been mitigated by mailing the survey earlier and determining the best manner to sample minority women.

\section{IMPLICATIONS FOR COMMUNITY HEALTH PROMOTION}

Some of the major implications for Community Health Promotion lie in causes of detrimental behaviors. For example, low self esteem is associated with body dissatisfaction. Developing an intervention for girls which targets self esteem may also promote greater body satisfaction. The importance of strengthening social norms cannot be overlooked. If young women perceive positive messages about their bodies from people who are important to them, they will be less likely to engage in detrimental behaviors. It is also important to consider the amount of time women and girls spend watching television. The media effects of comparing one's body to fashion models and celebrities have been shown to be associated with greater body dissatisfaction. Women can either avoid such images, or demand that the media show more realistic models. Finally, this survey demonstrated interventions are needed in the prevention and treatment of eating disorders. It appears there are significant associations between body image components and behavior which result from the interaction among those components. 


\section{REFERENCES}

Brown University Child and Adolescent Behavior Letter. (1999). Media has major impact on girls' body image. Brown University Child and Adolescent Behavior Letter, Vol. 15 Issue 5, 4-5.

Garner, D. and A. Kearney-Cooke (1996). Body Image 1996. Psychology Today, Vol. 29, Issue 2, 55.

Glanz, K., F. Lewis, and B. Rimer (1997). Health Behavior and Health Education: $2^{\text {nd }}$ Edition. San Francisco, CA: Jossey-Bass Publishers.

Grogan, S., Z. Williams, and M. Conner (1996). The Effects of Viewing SameGender Photographic Models on Body Esteem. Psychology of Women Quarterly, 20, $569-570$.

Henderson, A. (1995). Eating Disorders. Women's Health Weekly, 9/18/95, 18. Henriques, G. and L. Calhoun (1999). Gender and Ethnic Differences in the Relationship Between Body Esteem and Self Esteem. Journal of Psychology Interdisciplinary \& Applied, Vol. 133, Issue 4, 357.

Hoeger, W. and S. Hoeger (1997). Principles and Labs for Fitness and Wellness. Englewood, CO: Morton Publishing Company.

Joiner, G. and S. Kashubeck (1996). Acculturation, Body Image, Self Esteem, and Eating Disorder Symptomatology in Adolescent Mexican American Women. Psychology of Women Quarterly, 20, 419-421.

Kaw, E. in Weitz (1998) The Politics of Women's Bodies. Medicalization of Racial Features. New York: Oxford University Press. 
le Grange, D., C. Telch, and W.S. Agras (1995). Eating and General

Psychopathology in a Sample of Caucasian and Ethnic Minority Subjects. International Journal of Eating Disorders, 21, 285-293.

Lennon, S., A. Lillethun, and S. Buckland (1999). Attitudes Toward Social Comparisons as a Function of Self-Esteem: Idealized Appearance and Body Image. Family and Consumer Sciences Research Journal, Vol. 27, Issue 4, 379.

Mock, V. (1993). Body Image in Women Treated for Breast Cancer. Nursing Research, May/June 1993, 153.

Powell, A. and A. Kahn (1994). Racial Differences in Women's Desire to be Thin. International Journal of Eating Disorders, Vol. 17, 2, 191-195.

Psychology Today (1997). A Very Revealing Picture: Psychology Today's 1997 Body Image Survey Findings. Psychology Today, January/February 1997, 34-42.

Roid, G. and W. Fitts (1988). Tennessee Self Concept Scale: Revised Manual. Los Angeles: Western Psychological Services.

Rosenberg, M. (1965). The Rosenberg Self Esteem Scale. Society and The Adolescent Self Image. Krieger Publishing Company.

Smith, D., J. Thompson, J. Raczynski, and J. Hilner (1999). Body image among men and women in a biracial cohort: the CARDIA Study. International Journal of Eating Disorders, 1999 Jan., 71-82.

Stuhldreher, W. and W.Ryan (1999). Factors Associated with Distortion in Body Image Perception in College Women. American Journal of Health Studies, Vol. 15, Issue $1,8$. 
Wilfley, D., G. Schreiber, K. Pike, R. Striegel-Moore, D. Wright, and J. Rodin (1995). Eating Disturbance and Body Image: A Comparison of a Community Sample of Adult Black and White Women. International Journal of Eating Disorders, Vol. 20, 4, 377-387.

Yarborough, K. (2000). Understanding Body Image. The Center for Eating

Disorders. http://www.eating-disorders.com/news.htm 


\section{APPENDIX A}

March 17, 2000

\section{Dear student,}

You have been randomly selected to participate in a women's health study. This study is being conducted in partial fulfillment of the requirements for a master's thesis in Community Medicine/Community Health Promotion at West Virginia University. The purpose of this study is to determine how a variety of issues affect women's health. Your responses to this survey will be kept anonymous and confidential; and your name will not appear on your returned survey. You do not have to answer every question on the survey. In addition, your class standing, grades, job status, or status on an athletic team will not be affected by refusal to participate or withdraw from the study. Your participation in this study is entirely voluntary.

If you have any questions about this study, please contact Amy Rogers or Dr. Irene Tessaro at (304)293-0753. Your participation in this study is greatly appreciated.

Sincerely,

Amy Rogers

Enclosure: Health Study 


\section{APPENDIX B}

\section{HEALTH STUDY}

Thank you for taking the time to complete this questionnaire. Your answers will be anonymous and confidential, and you may refuse to answer any questions. By completing this questionnaire, you are giving permission for your responses to be used as part of a master's degree thesis on body image for the Department of Community Medicine and Community Health Promotion at West Virginia University. You must be 18 years of age or older to complete this survey. This questionnaire may take 10-15 minutes to complete. Please return this questionnaire in the enclosed envelope no later than May 12, 2000.

Please place a check mark or fill in your response.

1. Are you...

( ) Female ( ) Male

2. Your current class standing is...

( ) Freshman

( ) Sophomore

( ) Junior

( ) Senior

( ) Graduate Student

( ) No longer enrolled at WVU

( ) Other

3. How old are you?

4. On average, in the past year how often have you exercised per week?
( ) Never
( ) 1 time/week
( ) 2-3 times/week
( ) $4-5$ times/week
( ) 5-6 times/week
( ) 6-7 times/week

5. On average, how long do you exercise each time?
( ) 1-9 minutes
( ) 10-19 minutes
( ) 20-29 minutes
( ) 30-59 minutes
( ) 1-2 hours
( ) More than 2 hours

6. When you look at your body in the mirror, how satisfied do you feel about what you see?
( ) Very satisfied
( ) Somewhat satisfied
( ) Neutral
( ) Somewhat dissatisfied
( ) Very dissatisfied 
Please place a check mark under the letter that best corresponds to your responses to the following questions.

How important are the following in shaping the way you feel about your body?
A. Very important
B. Moderately important
C. Somewhat important
D. Somewhat unimportant
E. Moderately unimportant
F. Very Unimportant

A $\quad$ B $\quad$ C $\quad$ D $\quad$ E $\quad$ F

7. Not getting regular exercise.

8. Being around someone who you feel is critical of your body.....

9. Not living up to your family's standards of "looks"

( )

( )

( )

( )

10.Eating fattening foods

( )

11.Remembering being teased about your body when you were younger............. ( )

( ) ( ) ( ) ( )

12. A partner's opinion about

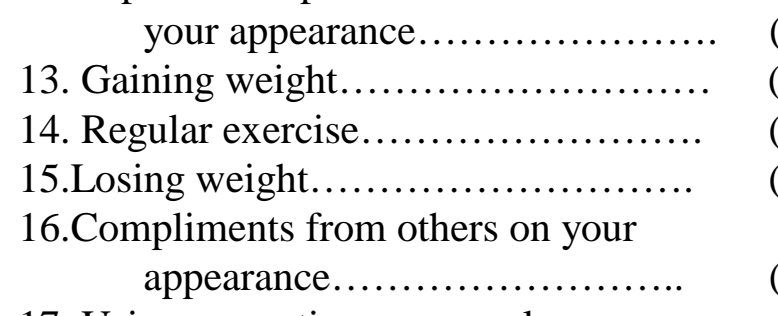

( ) ( ) ( ) ( ) ( ) ( )

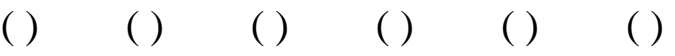

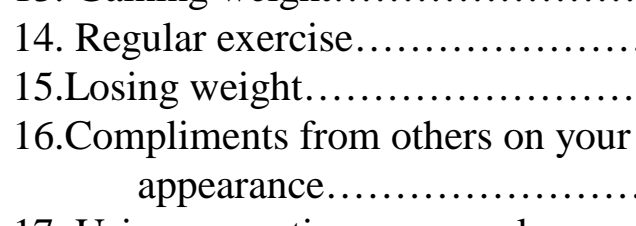

17. Using cosmetic or personal grooming products.................. ( )

18. Wearing flattering clothing............... ( )

19. Feeling "thin"........................... ( )

20. Eating low-fat foods.................... ( )

21. Plastic surgery........................ ( )

$\left(\begin{array}{llll}) & () & () & ()\end{array}\right.$

22. Fashion magazine models.................( )

$\begin{array}{llll}() & () & () & ()\end{array}$

23. Movie or television celebrities.............( )

( ) ( ) ( ) ( )

24 . How your mother feels about your

( ) ( ) ( ) ( )

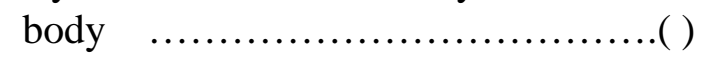

25 . How your father feels about your

() ()$\quad() \quad() \quad()$

body. ...

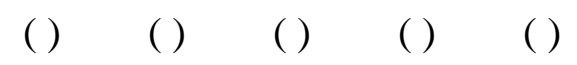

26. How your friends feel about your body. 
In the past year, which methods have you used to control your weight or lose weight (and how often)?
A. Never
B. Less than once a month
C. About once a month
D. About once a week
E. Two or more times a weeks

27. Diet pills

A $\quad$ B $\quad$ C $\quad$ D $\quad$ E

28. Laxatives.

( ) ( )

( ) ( ) ( )

29. Diuretics (water pills)

( ) ( )

( )

( )

( )

30. Exercise for weight los

( )

( )

( )

31.Self-induced vomiting

32.Extreme caloric restriction less than 500 calories/day.

\section{( ) ( )}

( )

33. Moderate caloric restriction.

34. Change in types of food eaten

( ) ( ) ( ) ( )

Please place a check mark next to your response.

35. Have you ever dieted to lose weight?
( ) No
( ) Yes

36. Have you ever followed a liquid-formula diet to lose weight?
( ) No
( ) Yes

37. Have you ever followed a commercial weight-loss program to lose weight?
( ) No
( ) Yes

38. Has anyone told you that you have an eating disorder? ( ) No

( ) Yes

38A. If YES, have you ever received treatment?

( ) No

( ) Yes

39. Do you intend to try to lose weight in the next 6 months?

( ) No ( ) Yes

40. Have you ever had plastic (cosmetic) surgery?

( ) No

( ) Yes

Please place a check mark under the letter that best corresponds to your response.
A. Always
B. Very Often
C. Often
D. Rarely
E. Never

41. How often do you compare yourself to

A B C $D$ E

models in magazines?

( ) ( ) (

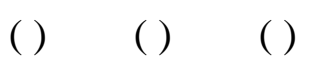


42. Do you carefully study the shapes of models in magazines?...................( )

43. Do you buy cosmetics or personal grooming products because of models?

Please answer the following questions on how much you agree with the following statements.
A. Strongly agree
B. Agree
C. Disagree
D. Strongly disagree

A $\quad$ B $\quad$ C $\quad$ D

44. On the whole I am satisfied with myself ....... ( ) ( ) ( ) ( )

45. At times I think am no good.................. ( ) ( ) ( ) ( )

46. I feel that I have a number of good qualities.... ( ) ( ) ( ) ()

47. On the whole I am satisfied with myself...........( ) ( ) ( ) ( )

48. At times I think am no good.................... ( ) ( ) ( ) ( )

49. I am able to do things as well as other people.... ( ) ( ) ( ) ( )

50. I feel I do not have much to be proud of........... ( ) ( ) ( ) ()

51. I certainly feel useless at times...................( ) ( ) ( ) ( )

52. I feel that I'm a person of worth, at least on an equal plane with others

53. I wish I could have more respect for myself...... ( ) ( ) ( ) ( )

54. All in all, I am inclined to feel that I am a failure.( ) ( ) ( ) ( )

55. I take a positive attitude toward myself...........( ) ( ) ( ) ( )

56. On the whole, I am satisfied with my body........( ) ( ) ( ) ( )

57. At times, I think I am unattractive ................ ( ) ( ) ( ) ( ) 
58. I feel that I have a number of good

physical qualities.

( ) ( ) ( ) ( )

59. People who are important to me

(parents, siblings, girlfriends, boyfriends) think

my appearance is just right....................... ( ) ( ) ( ) ( )

Please check or fill-in the following. Thank you for your responses.

60. I am....

( ) CAUCASIAN/WHITE (Non-Hispanic)

( ) HISPANIC/LATINA

( ) AFRICAN AMERICAN

( ) ASIAN/PACIFIC ISLANDER

( ) NATIVE AMERICAN

( ) MULTIRACIAL/OTHER (please specify)

61. My height is

62. My weight is

63. On average, how many hours of television do you watch every day?

The following organizations provide support for women who have concerns about their bodies.

West Virginia University Student Health Service (304) 293-6972

(Psychiatrists on staff)

West Virginia University Carruth Center (304) 293-4431

(Psychologists on staff)

The following numbers have been provided by "Something Fishy Website on Eating Disorders" at http://www.something-fishy.org. 
Eating Disorders Awareness and Prevention 1-800-931-2237

(Answers to questions, information and nationwide referrals)

1-800 THERAPIST Network 1-800-843-7274

(International mental health referral service)

American Anorexia and Bulimia Association (212) 575-6200

(Referrals to treatment and information)

Overeater's Anonymous (505) 891-2664

(Referrals to local chapters and information)

The National Mental Health Association Information Center

1-800-969-6642

(Referral to local Mental Health Association, who will help find community health services and self-help support groups) 